\title{
Energy-Efficient Electric Drive of the Cableway Supplied by the Mini- Hydroelectric Power Station
}

\author{
Pulat Sagitov, Yuriy Tcyba, Nurgul Almuratova* and Yuriy Kuzmin \\ Department of Electric Drive and Automation of Industrial Plants, Almaty University of Power \\ Engineering \& Telecommunications, Almaty, Republic of Kazakhstan; \\ sagitov.pulat@mail.ru, szyba46@mail.ru,nur0577@mail.ru,yorik_vuk@mail.ru
}

\begin{abstract}
Objectives: This paper deals with the problem of power supply of the electric drive of the cableway and its infrastructure provided by a mini-hydroelectric power station in the area of the Talgar-Issyk passage on the site chosen as a result of geodetic studies and satellite images. Methods/Analysis: It analyzes the hydropower potential of this area and offers a hydroelectric unit HU4 developed by MNTO INSET for a mini-hydroelectric power station. The problem is suggested to be solved through the use of internal resources of the regions. The equipment with the economical electric drive was selected for the cableway. Findings: Many scenic spots are located far away from power stations, and to provide an electric power line is not always possible, besides it is also quite an expensive and time-consuming process. The problem of power supply of the infrastructure necessary for recreation and tourism is relevant. The hydropower potential of Kazakhstan is measured at 170 billion kWh per year. However, the southern zone with hundreds of mountain small rivers has a $65 \%$ margin of hydropower resources of the republic where it is advisable to use micro- and mini-hydroelectric power stations. According to the calculations carried out in this research, the capacity needed for power supply of the electric drive of the cableway along with the infrastructure of the tourist camp is in the range of 500-600 kW. Applications: This paper will help to solve the problem of power supply of the electric drive of the cableway provided by a mini-hydroelectric power station. At the same time, the variable-frequency electric drive of the cableway will save a significant share of the electric power consumed from the mini-hydroelectric power station.
\end{abstract}

Keywords: Cableway, Energy-efficient Electric Drive, Mini-hydroelectric Power Station

\section{Introduction}

One of the global problems that arose at the dawn of the twenty-first century is man's dependence on energy sources. The basic method of its production is the use of natural sources - oil, gas, radioactive elements. These energy sources are, first, irreplaceable, and second, create the preconditions for environmental disasters. Energy conservation will help to prolong the limited supplies of high-quality fuels and to reserve a portion of fossil fuels for non-energy needs: the production of medicines, lubricants and other materials. It should be borne in mind that, as globally estimated, one monetary unit invested in energy efficiency corresponds by performance to five units invested in energy development and energy production.
In this regard, there is a need for not only energy efficiency but also for the development of environmentally friendly renewable energy sources.

In Kazakhstan, there is a considerable potential for the development of various sectors of the economy based on renewable energy sources such as biofuel, biogas, bioethanol, bio-, wind- and hydropower, as well as geothermal energy, solar energy, the use of which does not cause the greenhouse effect and the associated climate changen. The transition to renewable energy sources is also necessary because it is the basis for the development of high-tech industries given that there is a high scientific potentiall?

The Republic of Kazakhstan is known for its unique natural and geographical resources. The tourism industry

*Author for correspondence 
in Kazakhstan has been developed only since recently, however, in a relatively short period of time; this country was able to become one of the leading countries in the field of tourism in Central Asia, because Kazakhstan is rich in places of entertainment. However, for the development of tourism it is important that a country could "satisfy" its guests with services, which requires a strong infrastructure. At the same time, a necessary and important parameter for the creation of a favorable infrastructure for tourism is the electric power, as it is the cornerstones.

Many scenic spots are located far away from power stations, and to provide an electric power line is not always possible, besides it is also quite an expensive and time-consuming process. Therefore, today the problem of power supply of the infrastructure necessary for recreation and tourism is relevant.

Therefore, this paper, in accordance with the law on energy conservation and energy efficiency (published in the) and the Government Decree on the development of tourism businesses, solves the problem of power supply of the electric drive of the cableway provided by a minihydroelectric power station located in the area of the Talgar-Issyk passage. At the same time, the variablefrequency electric drive of the cableway will save a significant share of the electric power consumed from the mini-hydroelectric power station. In addition, this research analyzes the energy supply of the infrastructure designed to serve travelers and tourists, and the picturesque place chosen for the cableway is suitable for recreation and skiing and is easily accessible to residents of the metropolis:

\section{Methods}

The southern zone with the consumption of about $18 \%$ of its four areas has been experiencing a shortage of the electric power recently. Thermal stations of this zone run on imported fuel and imported gas, and the average operating power of stations, i.e. their readiness by technical conditions to issue power, is $23 \%$ of the installed capacity. This figure is a half times higher than the total value in Kazakhstan. This energy emergency is covered by supplies from the north of the republic for a thousand and more kilometers with heavy losses, and part of the energy is imported from neighboring countries

The hydropower potential of Kazakhstan is measured at 170 billion $\mathrm{kWh}$ per year. However, the southern zone with hundreds of mountain small rivers has a $65 \%$ margin of hydropower resources of the republic where it is advisable to use micro- and mini-hydroelectric power stationstr,2,3,

According to experts, in the south of Kazakhstan, it is possible to cover the energy shortage by building a cascade of environmentally friendly micro- and minihydroelectric power stations (without retaining dams) as far as the hydropower potential of the spurs of Zhetysu and Trans-Ili Alatau is estimated at no less than $4 \mathrm{GW}$ of capacity, which amounts to almost a quarter of the capacity of the southern energy. Of great importance are small hydroelectric power stations, the capacity of which is less than $10 \mathrm{MW}$. According to surveys, to date, there are at least 453 potential dam sites of small hydroelectric power stations with a total potential capacity of 1,380 MW. Some of these involve the use of existing irrigation channels that require lower cost, resources and time for their implementation. Only in Almaty region, the energy recourses of small rivers account for more than 2 billion $\mathrm{kW}-\mathrm{h}, \mathrm{f,6-8}$. In $\mathrm{P}$ shows a map of Almaty region with existing and planned small hydroelectric power stations.

In connection with this, this problem is suggested to be solved through the use of internal resources of the regions. Figure 1 shows a satellite photo of the selected area, promising for the construction of two cableways.

The use of the hydropower potential of Trans-Ili Alatau was based on the type of territory in the Talgar-Issyk passage with the use of water resources of the mountain river. The selection of the site was carried out according to the results of geodetic studies, satellite images, as well as the analysis of the hydropower potential of this area.

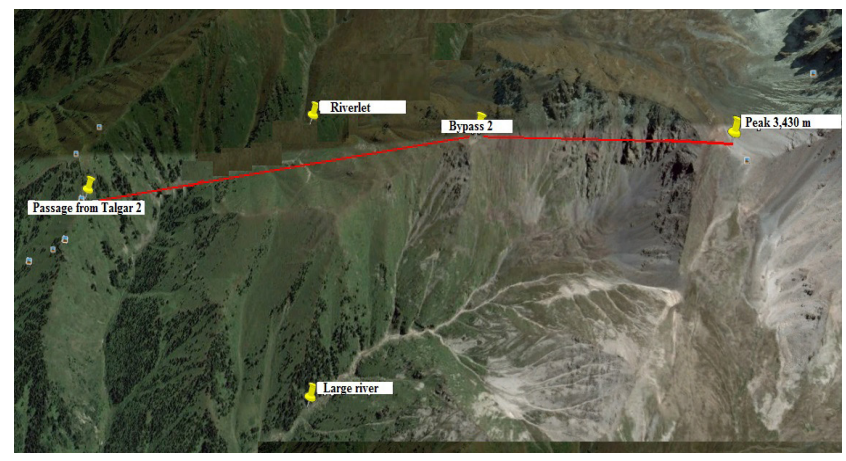

Figure 1. Satellite image of the Talgar-Issyk passage promising for construction of tourist facilities.

\section{Results and Discussion}

The cableway No.1 is a passenger gondola cableway with 
the length of 2,265 m, the landing place at the bottom, which is located at a height of 2,500 m above sea level and the landing site - at a height of 3,210 m. above sea level. Gondola is designed for 8 seats (Figure 2).

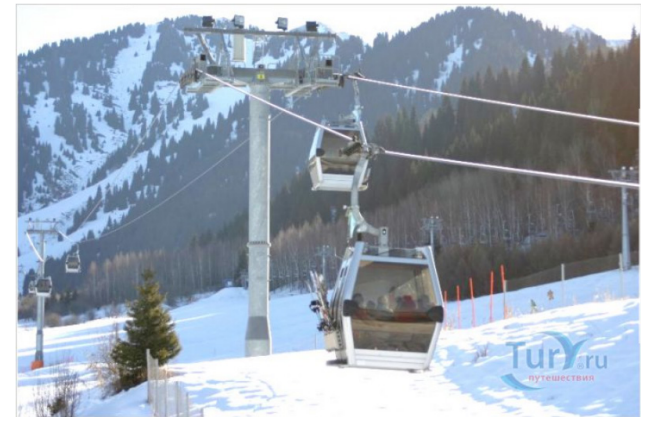

Figure 2. Photo of a passenger gondola cableway (photo of the ski resort Ak Bulak).

The site No.2 has a chairlift cableway with the length of $1,230 \mathrm{~m}$, the lowest landing point of $3,210 \mathrm{~m}$ above sea level and the top landing point of $3,430 \mathrm{~m}$ above sea level (Figure 3) .

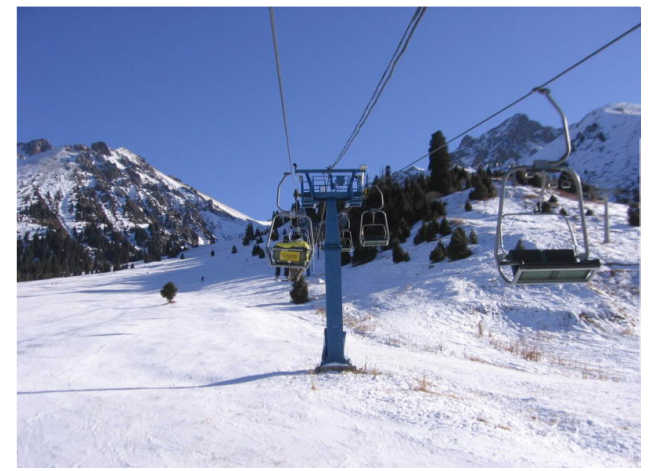

Figure 3. Photo of a chairlift cableway (photo of the ski resort Ak Bulak).

Questions of the use of energy-efficient technologies in the domestic energy sector have become more urgent recently and started to be addressed at all levels, while in Western countries this trend has been developed for quite a long timeto

Speaking about energy efficiency in the field of electric drive, there is a question on the use of frequency converters. The control of the motor speed in accordance with the requirement of maintaining a certain level of process parameters (pressure, flow, speed, etc.) helps to ensure energy conservation from $20 \%$ to $50 \%$, and in some plants, objects of housing and communal services, in particular, this figure may reach $70 \%$.
In addition to direct cost savings by reducing the consumption of the electric power, the application of frequency control helps to get additional effects, such as:

a) Reduction of shock loads at start-up:

- Start of the electric drive is carried out smoothly at the required rate of frequency increase ${ }^{17}$,

- Electrodynamic overload of motor winding and shock loads in the mechanism of the electric drive are excluded, which helps to reduce expenses for the repair and maintenance of motors and aggregates in general, and increases the service life of the equipment;

- Inrush starting current has a slight excess of the nominal, which reduces the requirements for the supply main and the adverse effect on other connected equipment;

b) Technological effects due to smooth speed control:

- Transition from one motor speed to another with the purpose to maintain a process variable at a desired level is carried out smoothly, which helps to increase the service life and reduce expenses for the repair and maintenance of pipelines and hydraulic fixtures by eliminating hydraulic and mechanical shock effects.

Frequency converters for low voltage motors (voltage class of up to $380 \mathrm{~V}$ ) are widely used and offered by both foreign and domestic enterprises- In the most common Variable-Frequency Drive (VFD), scalar and vector frequency control is used on the basis of asynchronous squirrel-cage motors.

In scalar control, the amplitude and frequency of the voltage applied to the motor is determined by a certain law. Changing the frequency of the supply voltage leads to a deviation from the calculated values of the maximum and starting torque of the motor, efficiency coefficient, and power factor. Therefore, to maintain the required motor performance, it is necessary to change the voltage amplitude along with the frequency ${ }^{11-13}$,

In the existing frequency converters with scalar control, the ratio of the maximum torque $M_{\max }$ to the shaft resistance torque $M_{r}$ is mostly kept constant. That is, when the frequency is changed, there is also a change in the voltage amplitude so that the ratio of the maximum torque of the motor to the current load torque remains unchanged. This ratio is called the overload capacity of the motor. When the overload capacity is steady, the rated power factor and efficiency coefficient of the motor 
are practically unchanged on the whole range of speed frequency control.

Therefore, if control objects have a constant dead load torque of $M_{r}=$ Const, the voltage of the power source should vary in proportion to its frequency $U / f=$ const. In control objects that require speed control at the constant capacity of $C s=$ Const, the control law will be $U / \sqrt{ } f=$ const, and in the fan load the control law corresponds to $U / f^{2}=$ const. For these reasons, the most widely used control method for mechanisms is $M_{r}=$ Const, although in principle the use of functional converters helps to implement any of these lawst.

An important advantage of the scalar method is the possibility to simultaneously control a group of electric motors. Scalar control is sufficient for most practical applications of the variable-frequency electric drive with a range of motor speed control of up to $1: 40$ 2,1,

Upper speed control is possible in the range of 2:1 and limited by the durability of rotor windings. Down control is limited to $15: 1$, which is caused by the complexity of implementing the power source with the low frequency. The use of specially designed motors extends the range by increasing the upper limit speed.

Vector control can significantly increase the range of control, control accuracy, speed of the electric drive. This method provides the direct control of the motor torque ${ }^{2}$. The driving motor torque is determined by the stator current, which creates an energizing magnetic field. With direct torque control, it is necessary to change not only the amplitude but also the phase of the stator current, i.e. the current vector. This explains the term "vector control" $, 9,12$,

To control the current vector, and thus the position of the stator magnetic flux in relation to the rotating rotor, one need to know the exact position of the rotor at any given time. The problem is solved either by the remote rotor position sensor or by the determination of the rotor position through calculations on other motor parameters. These parameters can include currents and voltages of stator windings.

Less expensive is the variable-frequency electric drive with vector control without the rate feedback sensor. However, vector control, at the same time, requires a large volume and high computational speed from the frequency converter. In addition, for direct torque control at low and close to zero rotation rates, the performance of the VFD is impossible without rate feedback 1,12 .

Vector control with the rate feedback sensor provides a control range of up to 1:1000 and higher, the control rate accuracy - hundredths of a percent, the torque accuracy - a few percent.

The synchronous VFD uses the same control methods as asynchronous. However, in pure form, the frequency control of synchronous motors speed is only applied at a low capacity when the load torque is small, and the inertia of the drive mechanism is low. At a high capacity, only the drive with the fan load fully meets these requirements. In the cases of other load types, the motor may fall out of synchronisme.,

In accordance with the above, for the VFD cableway one must use scalar control by the law of $U / f=$ const at the rate stabilization, since there is no need for a wide control range and its accuracy and speed.

Figure 4 shows a satellite image of the existing and planned cableways of Almaty region.

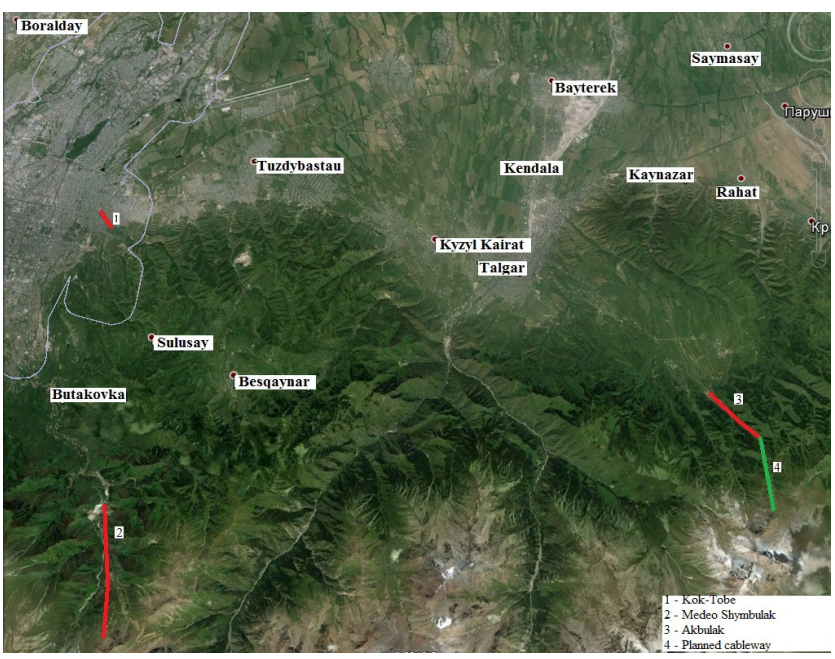

Figure 4. Satellite image of the existing and planned cableways of Almaty region.

As noted above, the cableway is divided into two sites. The cableway No.1 is a passenger gondola cableway with the length of 2,265 m, the landing place at the bottom, which is located at a height of 2,500 m above sea level and the landing site - at a height of $3,210 \mathrm{~m}$. above sea level (position 4). The site No.2 has a chairlift cableway with the length of $1,230 \mathrm{~m}$, the lowest landing point of 3,210 m above sea level and the top landing point of $3,430 \mathrm{~m}$ above sea level (position 4).

The cableway under consideration refers to the airlift with the centralized (cable) traction - the so-called aerial cableway, in which all the carriages on the line are connected to the endless traction cable having a fixed 
drive. In the intermediate and final stations, carriages can be disconnected from the traction cable and moved by hand, gravity, or by using mechanical devices for overhead tracks; tracks with the help of arrows, crosses and other conversion devices can have any branchesf

The cable traction does not require the connection of running wheels with the track and therefore allows a cableway to have steep slopes and very long spans between supports. The length of the cableways is not limited, and the ways with the great length consist of a series of consecutive drives with intermediate stations. The road layout may be shaped as a broken line with the corner intermediate stations.

The proposed cableway has a bi-cable mode in which there are two kinds of cables: carrying cables, where the running carriage wheels are rolling, and a traction cable, by which the movement of the carriage is performed (Figure 5).

When replacing the carrying cable along the whole length (or part) of the cableway with a hanging rail, the bi-cable cableway turns into an aerial railway with the cable traction.

Technical data:

1. The travel distance of the cableways: $1-2,265 \mathrm{~m}$; $2-1,230 \mathrm{~m}$;

2. The difference between the start and end of travel: 1 - $710 \mathrm{~m} ; 2$ - $320 \mathrm{~m}$;

3. The speed of carriages: $6 \mathrm{~m} / \mathrm{s}$;

4. The strength of the traction cable:

Braking mode: $26,000 \mathrm{~N}$,

Traction mode: $45,000 \mathrm{~N}$ on the site No.1, and $38,000 \mathrm{~N}$ on the site No.2;

5. The weight of the progressively moving parts: 103 * $103 \mathrm{~kg}$;
6. The gearbox ratio: 21.2 ;

7. The efficiency coefficient of the cableway: 0.88 ;

8. The drum diameter: $5 \mathrm{~m}$ - for the gondola cableway on the site No.1, and $4 \mathrm{~m}$ - for the chairlift cableway on the site No.2;

9. The moment of inertia of the rotating parts: 1,800 $\mathrm{kg}^{\star} \mathrm{m}^{2}$

\section{Specifications:}

1. AC main, voltage of $380 \mathrm{~V}$.

2. The power source of asynchronous motors variable-frequency converters.

3. Time of the traction and braking mode of operation is the same.

4. The speed of $3 \mathrm{~m} / \mathrm{s}$ at the load of $50 \%$ should be ensured for auditing.

5. To stop moving, dynamic braking is applied with the mechanical brake at the end of braking.

According to the calculated values of the load and speed of the gondola and chairlift cableways, the asynchronous motors AIR355M4 and AIR355M8 respectively were proposed ${ }^{15-17}$.

On the basis of motor power and the necessary technical requirements to the electric drive of materialhandling equipment, the most optimal frequency converters are those of Altivar 71 of the type 1/IP 20, (ATV 71HxxxN4), which are designed for the motors with a capacity of $0.37 \mathrm{~kW}$ to $500 \mathrm{~kW}$ with three types of power supply 12,18 .

One of the features of the new Altivar series is a very small size with the integrated electromagnetic compatibility filter (Figure 6). This characteristic as well as the ability to install them close to each other can significantly save space in the electric equipment cabinet. Uninterrupted operation of the electric drive with Altivar

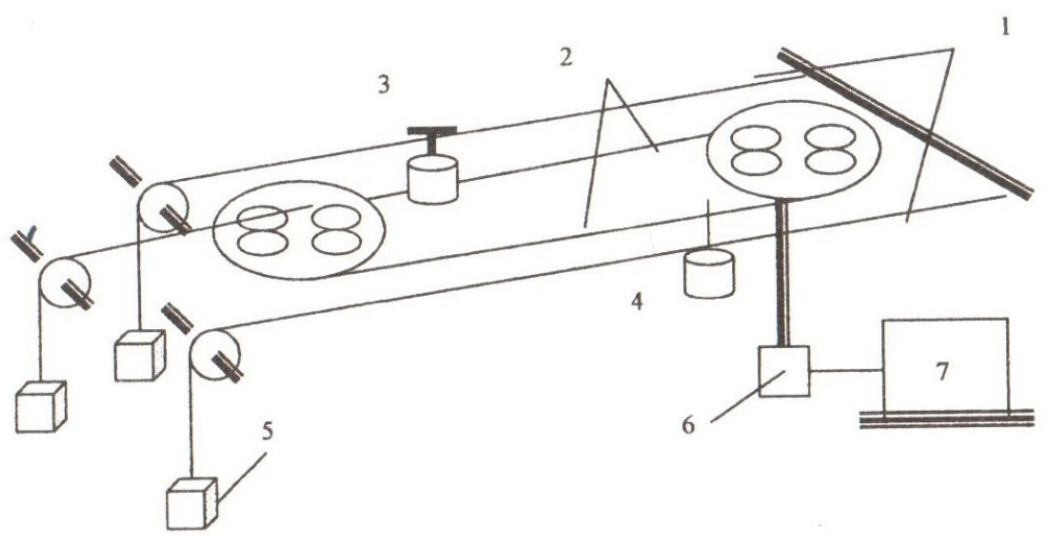

Note. 1 - carrying cables; 2 - continuous rope for transmission of traction power; 3 - rolling supports; 4 -passenger carriages; 5 - loads of carrying and leading ropes; 6 - gearbox; 7 - motor.

Figure 5. Kinematic scheme of the cableway?. 
is guaranteed in severe climatic conditions from $-10^{\circ} \mathrm{C}$ to $50^{\circ} \mathrm{C}$ without derating.

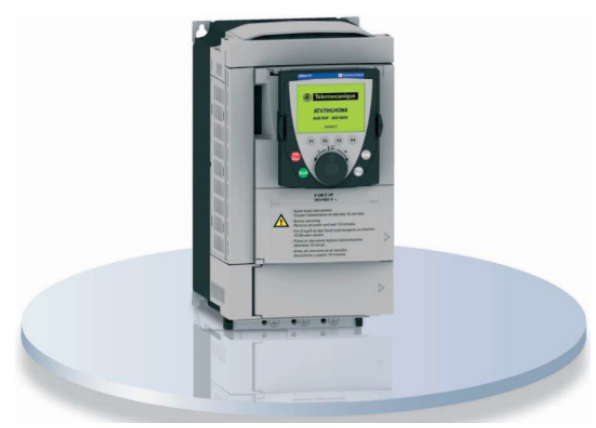

Figure 6. A series of Altivar 7 frequency converterst 1 .

Altivar 71 meets the most stringent requirements of applications due to the use of a variety of motor control laws and its many functional capabilities. It is adapted to solve the most complex problems of the electric drive f $^{\text {, }}$

The electric drive is made on the basis of the twolink frequency converter with the transistor (IGBT) autonomous voltage inverter, pulse-duration control and a multifunctional microprocessor control system with the advanced interface. The principle of operation and the mechanism of the electric drive is illustrated in the functional diagram in Figure $70,12,19$.

The speed controller of the electric drive is realized with the help of the P and PI controllers. To implement the
PI controller, one need to take the cell of the SC-IAI speed controller with the $\mathrm{P}$ controller, and the A-I2AI amplifier. In parallel, the Ros resistance is on for the amplifier. The scheme of the PI controller is shown in Figure 8.

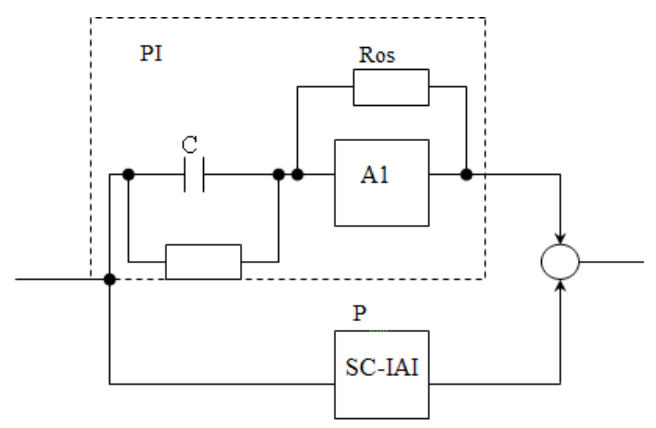

Figure 8. The realization of the PI controller in the electric drive 月 $^{\text {. }}$

The economic potential of micro- and minihydroelectric power stations is about $10 \%$ of the total economic potential of renewable energy sources. However, less than $0.1 \%$ of this potential is currently used in Kazakhstan.

New modular models of the damless microhydroelectric power station have been developed by Kazakh scientists and engineers, who received provisional patents, made a prototype sample and carried out an experiment. The test results proved the high efficiency

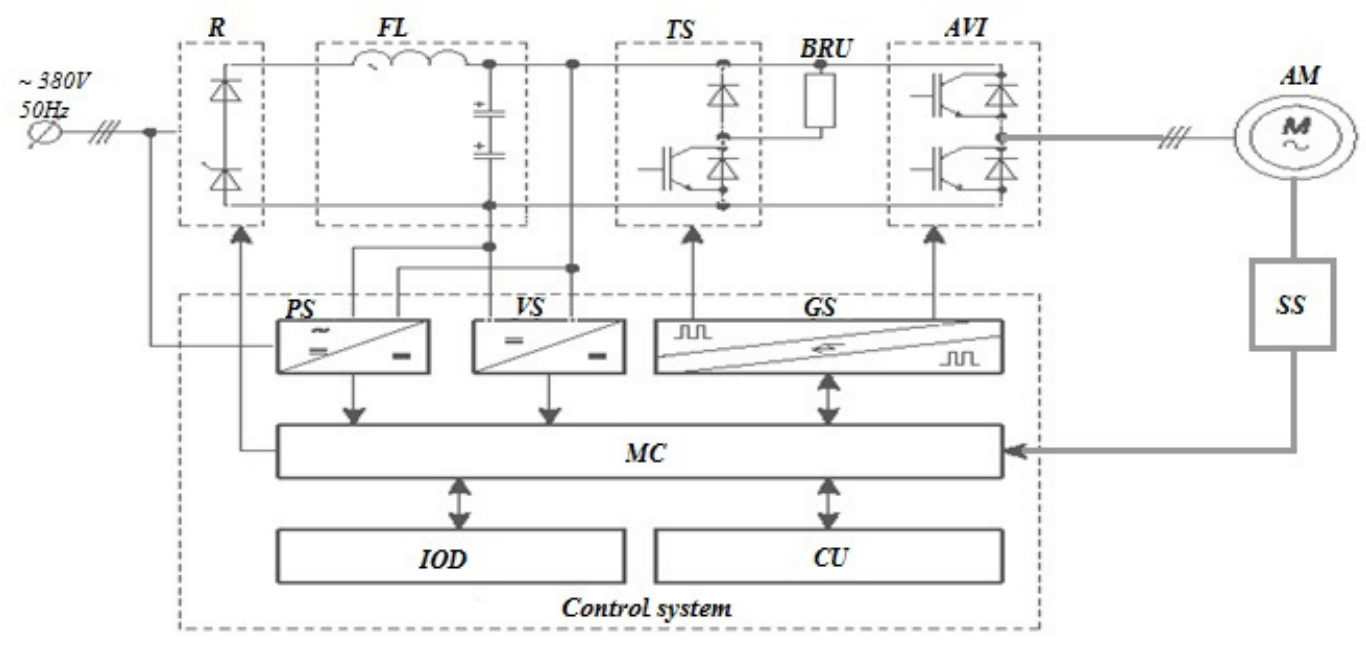

Note: AM - driving asynchronous motor; PS - power source (converter); VS - voltage sensor; GS - generator of control transistor signals (driver); MC - microprocessor controller; IOD - input / output device (external interface); CU - control unit; R - half-controlled power (diode-thyristor) rectifier; FL - power LC - filter of DC voltage link; TS - transistor (IGBT) dynamic braking switch installed in AT04; BRU - external braking resistor unit; AVI - transistor (IGBT) autonomous voltage inverter; CS - current sensor.

Figure 7. Functional diagram of the electric drive of the cableway' 
of the developed structure of micro-hydroelectric power stations and their competitiveness in both domestic and international market, ,5-g,

Many of the developments of Kazakh scientists such as micro-hydroelectric power stations have been successfully tested, for example, the installation of the micro-hydroelectric power station-1, developed by the RSE "Scientific and Practical Centre for Agricultural Mechanization". Its generated power of $1 \mathrm{~kW}$ at a flow rate of $0.32 \mathrm{~m}^{2} / \mathrm{s}$ and water pressure of $4 \mathrm{~m}$ is sufficient to supply power to a breeder's housing in the field environment. The Almaty Institute of Energy and Communications has developed the experimental mountain mini-hydroelectric power stations of the diversion and fuel type $e^{4,22}$.

Figure 9 shows a map of Almaty region with the existing and planned small hydroelectric power stations, where $\mathrm{X}$ determines the site intended for the construction of the cableway. In this area, as seen from a satellite photo of the Talgar-Issyk passage (Figure 1), there is a big mountain river in the gorge "Sukhoi Log". The hydropower potential of this river is proposed to be used for the power supply of the energy-efficient variable-frequency drive of the cableway, which will save a considerable share of the electric power consumed from the mini-hydroelectric power station.

It is known that the use of the damless sleeve minihydroelectric power station helps to develop $550 \mathrm{~kW}$ to $1 \mathrm{~mW}$ of the electric power, which is enough to provide for the infrastructure of a tourist ski resort, as well as to supple power of the electric drive of the cableway with the total power consumption of $475 \mathrm{~kW}$, according to estimates ${ }^{4,5,13,20}$

Figure 10 shows a diagram of the damless minihydroelectric power station, which is proposed to be positioned at a major river in the gorge of "Sukhoi Log" (Figure 1).

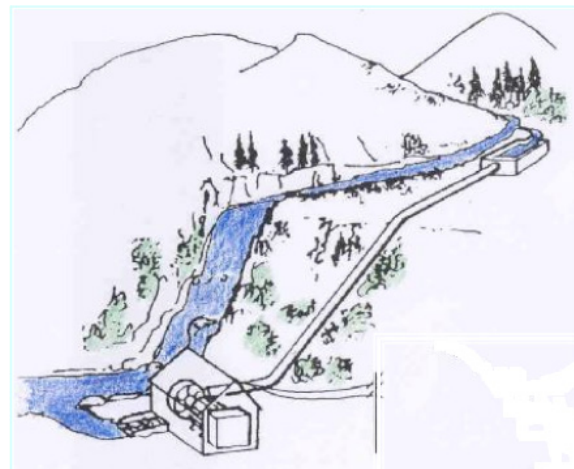

Figure 10. Scheme of the damless sleeve mini-hydroelectric power station.

Power, carrying out the work of the water flow, is water weight. The work of the flow is determined by the pressure (P) of a watercourse, i.e. the difference of water levels at the beginning and end of the site under consideration, and the flow rate $(\mathrm{Q})$ of flowing water ${ }^{5,21}$.

If the fall of the water surface of the length of $L$ meters

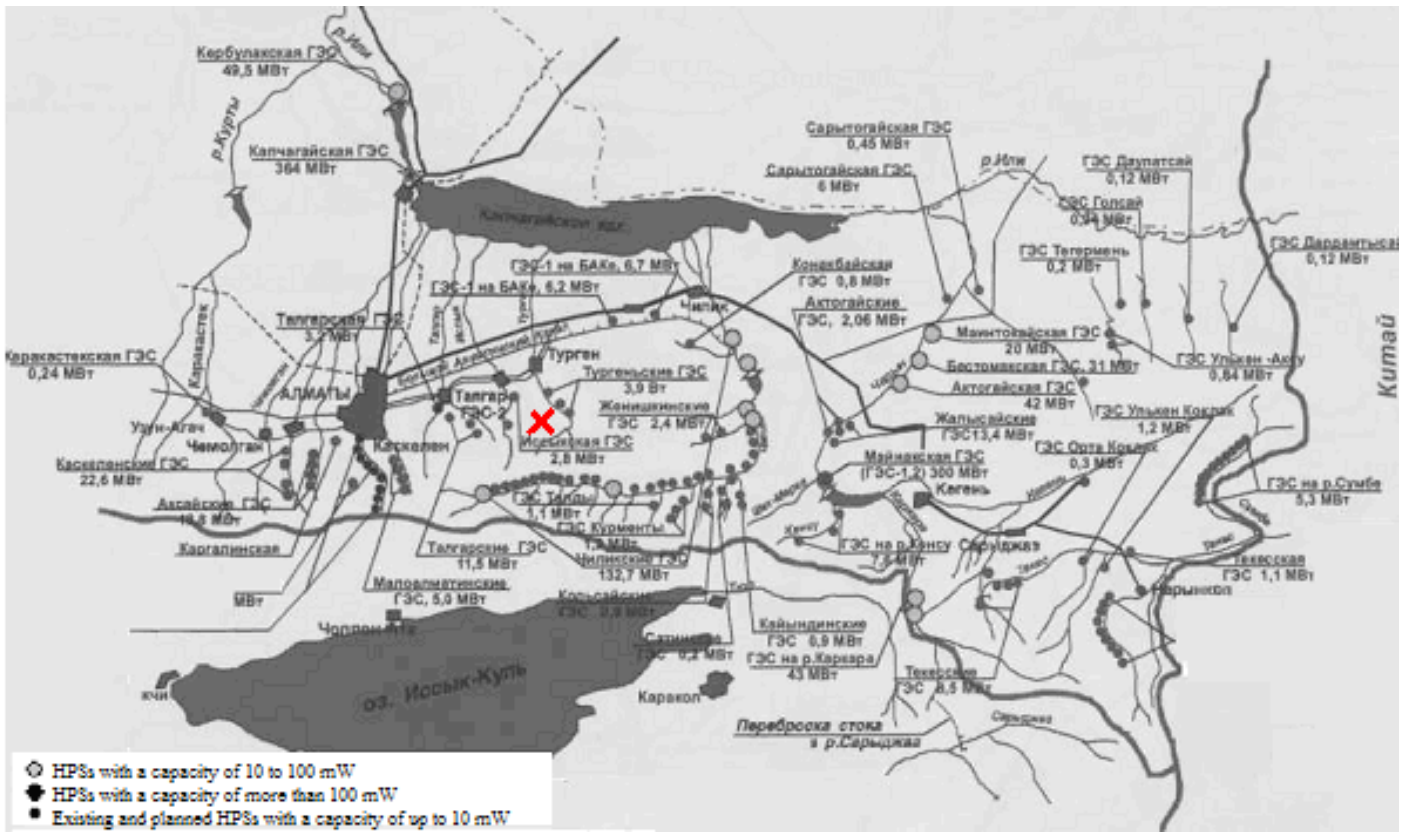

Figure 9. Map of Almaty region with existing and planned small Hydroelectric Power Stations (HPS) 
is $\mathrm{H}$ meters in length, then at a flow rate of $\mathrm{Q}, \mathrm{m}^{3} / \mathrm{s}$, equal to its average value at the beginning and end of the site, the work of flowing water in 1 second, i.e. the capacity of a watercourse $\mathrm{N}, \mathrm{W}$, in the site under consideration will be:

\section{$\mathrm{N}=\rho \cdot \mathrm{g} \cdot \mathrm{Q} \cdot \mathrm{H}=9810 \mathrm{Q} \cdot \mathrm{H}$,}

where $\rho$ - water density, $\mathrm{kg} / \mathrm{m}^{3} ; \mathrm{g}$ - acceleration of gravity, $\mathrm{m} / \mathrm{s}^{2}$.

Since all the kinetic energy of the water flow cannot be converted into the electric power, it is necessary to supplement the above equation with the mechanical efficiency coefficient of the hydraulic unit $\eta$ (in the range of 0.6 to 0.95 , depending on the type of the hydraulic unit).

Thus, the estimated power supplied by micro- or mini-hydroelectric power stations in watts is as follows:

\section{$\mathrm{N}=\rho \cdot \mathrm{g} \cdot \mathrm{Q} \cdot \mathrm{H} \cdot \eta \approx \mathbf{8 8 0 0} \mathrm{Q} \cdot \mathrm{H}$}

Pressure is the liquid head expressed by the height of a liquid column above the selected reference level, or the difference of levels from the water withdrawal in the system to the hydraulic unit; measured in meters?

A range of the equipment manufactured by MNTO INSET is focused on the creation of the environmentally friendly equipment for micro and small hydroelectric power stations. With its help, one could provide the electric power to people living in remote and mountainous areas, as well as farms. It is much cheaper and more profitable than the construction of power lines or diesel plants operation.

Figure 11 shows a photo of the hydraulic unit of the mini-hydroelectric power station ${ }^{1-23}$.

Figure 12 shows a photo of the machine room of the damless sleeve mini-hydroelectric power station.
Table 1 shows technical ranges of mini-hydroelectric power stations produced by MNTO INSET 2 .

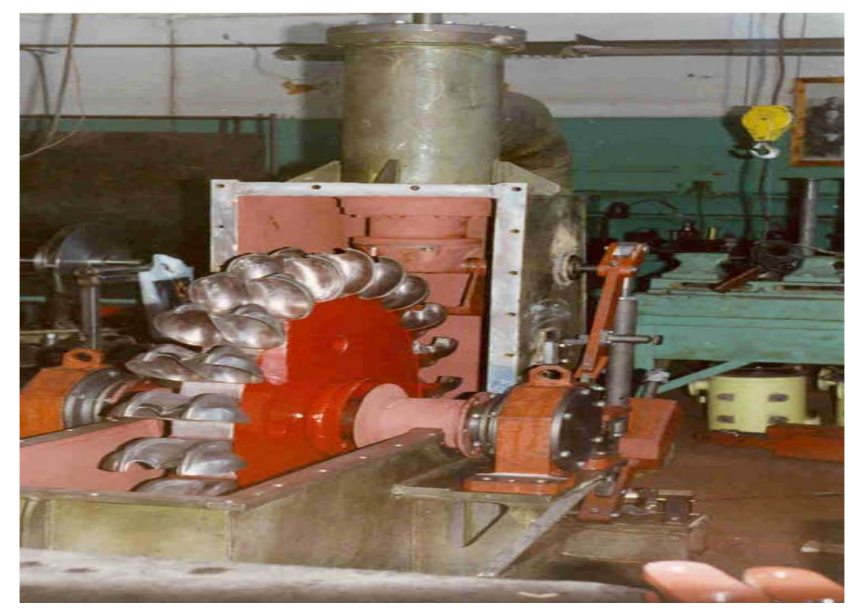

Figure 11. Photo of the hydraulic unit

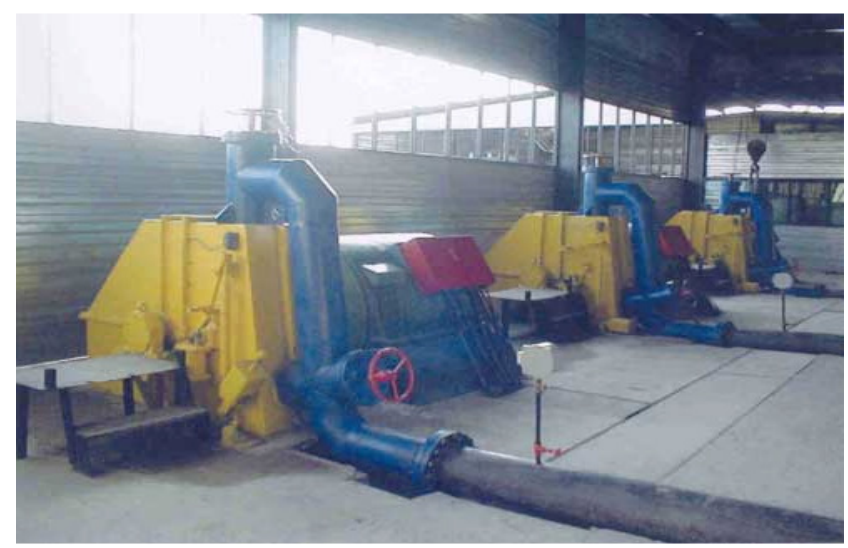

Figure 12. Photo of the machine room of the damless sleeve mini-hydroelectric power station

Figure 13 shows a diagram of capacities for selecting the type of the hydraulic turbine depending on the pressure $\mathrm{P}(\mathrm{m})$ and the flow rate $\mathrm{Q}(\mathrm{l} / \mathrm{s})$.

Table 1. Nominal values of hydraulic units produced by MNTO INSET

\begin{tabular}{lcccc}
\hline Parameters & \multicolumn{4}{c}{ Type of the hydraulic unit } \\
\cline { 2 - 5 } & HU2 & HU4 & HU9 & HU11 \\
\hline Capacity,kW & up to 950 & 550 & 3300 & 5600 \\
Pressure, $\mathrm{m}$ & $30-100$ & $25-55$ & $70-120$ & $100-160$ \\
Flow rate, $\mathrm{m}^{3} / \mathrm{s}$ & $0,35-0,9$ & $0,4-1,0$ & $0,8-3,2$ & $1,5-4,0$ \\
Frequency of turbine rotor spinning, min $^{-1}$ & $1000 ; 1500$ & 1000 & $600 ; 750 ; 1000$ & $750 ; 1000$ \\
Nominal voltage, $\mathrm{V}$ & $400 ; 6000$ & $400 ; 6000$ & $6000 ; 10000$ & $6000 ; 10000$ \\
Nominal current frequency, $\mathrm{Hz}$ & 50 & 50 & 50 & 50 \\
\hline
\end{tabular}




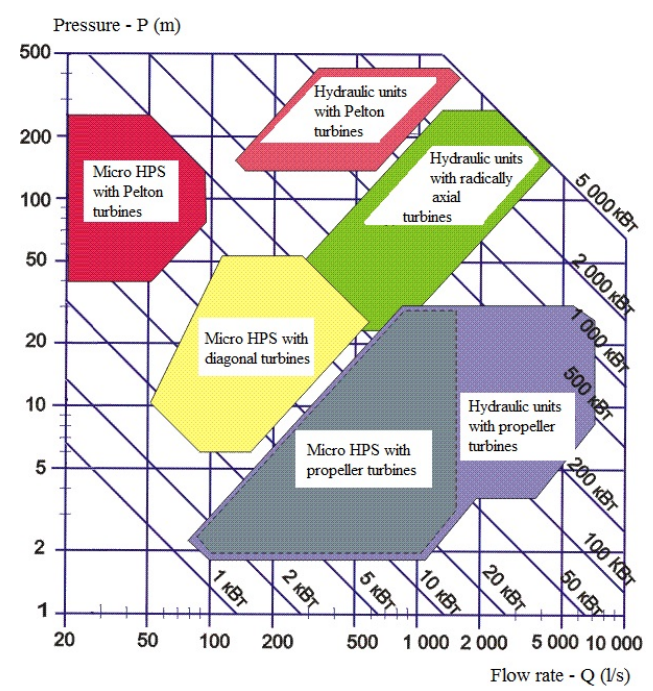

Note: $\mathrm{KBT}-\mathrm{kW}$.

Figure 13. Diagram for selecting the type of the hydraulic turbine

According to the above calculations, the capacity needed for power supply of the electric drive of the cableway along with the infrastructure of the tourist camp is in the range of 500-600 $\mathrm{kW}^{\square, 2,2}$. Therefore, according to the data in Table 1 and the diagram for selecting the type of the hydraulic turbine in Figure 11, as well as the analysis of the hydropower potential of the area, the hydraulic unit HU4 of MNTO INSET with a capacity of $550 \mathrm{~kW}$ is the most optimal for mini-hydroelectric power stations.

Stability enhancement and control in power systems was also analyzed by 5 -2 2 , who approached a number of algorithms, including PSO, ACO algorithm, ABC algorithm et al. for optimization of power systems. The issue of energy supply and conservation was studied by ${ }^{29-31}$ Therefore, it can be seen that this research addresses a relevant issue, which plays an important role in the industrial development and energy security.

\section{Conclusions}

The present paper has considered the possibility of power supply of the cableway provided by a mini-hydroelectric power station installed on the mountain river. The equipment with the economical electric drive was selected for the cableway. According to the calculated values of the load and speed of the gondola and chairlift cableways, the asynchronous motors AIR355M4 and AIR355M8 respectively were proposed.
On the basis of motor power and the necessary technical requirements to the electric drive of materialhandling equipment, the most optimal frequency converters are those of Altivar 71 of the type 1/IP 20, (ATV 71HxxxN4), which are designed for the motors with a capacity of $0.37 \mathrm{~kW}$ to $500 \mathrm{~kW}$ with three types of power supply.

One of the features of the new Altivar series consists in a very small size with the integrated electromagnetic compatibility filter. This characteristic as well as the ability to install them close to each other can significantly save space in the electric equipment cabinet. Uninterrupted operation of the electric drive with Altivar is guaranteed in severe climatic conditions from $-10^{\circ} \mathrm{C}$ to $50^{\circ} \mathrm{C}$ without derating.

Altivar 71 meets the most stringent requirements of applications due to the use of a variety of motor control laws and its many functional capabilities. It is adapted to solve the most complex problems of the electric drive. The electric drive is made on the basis of the twolink frequency converter with the transistor (IGBT) autonomous voltage inverter, pulse-duration control and a multifunctional microprocessor control system with the advanced interface.

According to a satellite photo of the Talgar-Issyk passage, there is a big mountain river in the gorge "Sukhoi Log" in this area. The hydropower potential of this river is proposed to be used for the power supply of the energyefficient variable-frequency drive of the cableway, which will save a considerable share of the electric power consumed from the mini-hydroelectric power station.

The equipment manufactured by MNTO INSET, which is focused on the creation of the environmentally friendly equipment for micro and small hydroelectric power stations, was selected for the research. It was proved that with its help, one could provide the electric power to people living in remote and mountainous areas, as well as farms. It is much cheaper and more profitable than the construction of power lines or diesel plants operation.

According to the calculations carried out in this research, the capacity needed for power supply of the electric drive of the cableway along with the infrastructure of the tourist camp is in the range of 500-600 kW. It was found out that the hydraulic unit HU4 of MNTO INSET with a capacity of $550 \mathrm{~kW}$ is the most optimal for minihydroelectric power stations. 


\section{References}

1. Sibikin YD, Sibikin MY. Alternative and renewable energy sources. Moscow: KNORUS; 2010.

2. Bolotov AV. Alternative and renewable energy sources: Textbook. Almaty: AUPET; 2011.

3. Dukelskiy AI. Aerial ropeways and cable cranes. Moscow: Mashinostroyeniye; 2006.

4. Tcyba YA. Energy efficiency in the power sector: Textbook. Almaty: AUPET; 2011.

5. Mukazhanov VN. Renewable energy sources: Textbook. Almaty: AUPET; 2011.

6. Chodzhoy MH. Energy efficiency in the industry. Moscow: Metallurgia; 1982.

7. Leznov BS. Energy saving in pump installations. Moscow: Energoatomisdat; 1991.

8. Samoylov MV, Panovchik VV, Konovalov AN. Basics of energy conservation: Textbook. $2^{\text {nd }}$ ed. Minsk: Belarusian State Economic University; 2003.

9. Vinogradov AB. Vectorial control of alternating current of electrical drives. Ivanovo; 2008. p. 187-95.

10. Terekhov VM, Osipov OI. Systems of electric drive control: Textbook. Moscow: Academia; 2008.

11. Sagitov PI. Energy saving in the electric drive: Textbook. Almaty: AUPET; 2005.

12. Cathey JJ, Famouri P. Loss minimization of an induction motor drive. IEEE Transactions on Industry Applications1991 Jan/Feb; 27(1):32-7.

13. Kolesnikov AI, Fedorov MN, Varfolomeyev YM. Energy conservation in industrial and public enterprises. Moscow: INFRA-M; 2005.

14. Arutyunyan AA. Basics of energy conservation. Moscow: JSC “Energoservis"; 2007.

15. Asinkhronnye dvigateli firmy ABB [Asynchronous motors of the ABB firm] [Internet]. Available from: www.abb.com/ motors.

16. Asinkhronnye dvigateli firmy Siemens [Asynchronous motors of the Siemens firm] [Internet]. Available from: http:// electrosiemens.ru/.

17. Malakhanov AA. Mathematical simulation of impact and module systems with correction of power coefficient. $\mathrm{PhD}$ Thesis, Bryansk; 2007.p. 16.
18. Galler D. Energy efficient control of AC induction motor vehicles. IEEE Transactions on Industry Applications. 1980 Annual Meeting.1980 Sep. p. 301-8.

19. Altivar 71 background material converter [Internet].2016. Available from: www.electrocentr.com.

20. Polonskiy VM, Trutneva MS. Energy conservation: Textbook. Moscow: Publishing House of the Association of Building Universities; 2005.

21. Small hydro international gateway [Internet]. Available from: http://www.small-hydro.com.

22. AFREPREN/FWD - Energy, environment and development network for Africa [Internet]. [cited 2016 Nov 18]. Available from: Website: http://www.afrepren.org.

23. MNTO INSET [Internet]. Available from: www.inset.ru.

24. Terekhin VB. Simulation of electric drive systems in Simulink (Matlab 7.0.1): Textbook. Tomsk: Publishing House of Tomsk Polytechnic University; 2008.

25. Kasilingam, G, Pasupuleti, J. Coordination of PSS and PID controller for power system stability enhancement - overview. Indian Journal of Science and Technology. 2015 Jan; $8(2): 142-51$.

26. Rout KC, Panda PC. Power system dynamic stability enhancement of SMIB using fuzzy logic based power system stabilizer. Power Electronics and Instrumentation Engineering. 2010 Sep; 102:10-14.

27. Sheeba R, Jayaraju M, Kinattingal. Performance enhancement of power system stabilizer through colony of foraging ants. Electric Power Components and Systems. 2014 Mar; 42(10):1016-28.

28. Zhukov IB, Lazarev EA. Procedure of selecting optimum capacity and voltage for an on-board electric power supply system accumulator. Indian Journal of Science and Technology. 2016 Oct; 9(39):1-9.

29. Mufti GM, Jamil M, Nawaz M, Mobeen-ur-Rehman, Hassan SZ, Kamal T. Evaluating the issues and challenges in context of the energy crisis of Pakistan. Indian Journal of Science and Technology. 2016 Sep; 9(36):1-7.

30. Bae S, Yun JJ. Economic and energy efficient design method for a green wireless telecommunication power system. Indian Journal of Science and Technology. 2015 Oct; 8(26):1-6.

31. Roy S, Mishra H, Mohapatro BG. Sustainable environment using smart materials in smart structures. Indian Journal of Science and Technology. 2016 Aug; 9(30):1-9. 